\title{
EFFECT OF AEROBIC DANCE ON PAIN, FUNCTIONAL DISABILITY AND QUALITY OF LIFE ON PATIENTS WITH CHRONIC LOW BACK PAIN
}

\begin{abstract}
Low back pain (LBP) is often an indication of pathological condition of the intervertebral discs, vertebral bodies or supporting soft tissues of the lower vertebral region. Chronic Low Back Pain (CLBP) presents with enormous consequence on the general performance of the sufferer, exerting a huge cost on the individual, the family and the society. Dance therapy is a relatively new approach in the management of low back pain. This study was therefore designed to investigate the effect of dance therapy on pain, functional disability and quality of life in patients with chronic low back pain.

Thirty subjects diagnosed with non-specific CLBP particpated in the study. They were randomly divided into 2 groups, $A$ and $B$, each comprising 15 subjects.

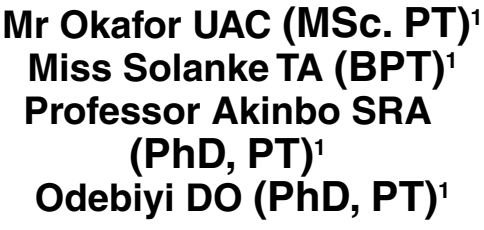

Mr Okafor UAC (MSc. PT) ${ }^{1}$

Miss Solanke TA (BPT) ${ }^{1}$

Professor Akinbo SRA

(PhD, PT) ${ }^{1}$

Odebiyi DO (PhD, PT) ${ }^{1}$

Physiotherapy Department,

University of Lagos,

Lagos, Nigeria.

In addition to conventional physiotherapy programme given to both groups,

subjects in Group A also received aerobic dance, which comprised a four stage protocol. The entire treatment routine was administered in a group session three times weekly consecutively for six weeks. Data as obtained in the copies of completed questionnaires (Roland Morris Diability questionnaires and Nottingham Health Profile questionnaires) and other measurements were summarized using mean, standard deviation and frequency tables. Student T-test was used to analyze the data at $95 \%$ confidence interval.

There was a statistically significant difference $(p<0.05)$ between the pre-and post-intervention scores for pain intensity, functional disability and quality of life within the groups. There was also a statistically significant difference $(p<0.05)$ in the mean change (pre/post intervention) scores between Group A and Group B for pain intensity, functional disability and quality of life. Also the opinions and testimonies given by participants formed part of the evidence-based data.

Whereas both conventional physiotherapy and aerobic dance showed significant effects in the pre/post-intervention scores, the aerobic dance group reported more significant effect in all studied parameters of pain intensity, functional disability and quality of life.
\end{abstract}

\section{KEY WORDS: CLBP, FUNCTIONAL DISABILITY, QUALITY OF LIFE, AEROBIC DANCE.}

\section{INTRODUCTION}

Low back pain (LBP) has been reported as the second leading reason for visiting the doctor in the United States of America, third most common reason for surgical procedures, fifth most common reason for hospital admission, most frequent cause of disability for people younger than 45 years of age and the most common painful condition reported by patients after headache Koes $B$ and Van-Tudler M (2006). LBP is often an indication of pathological condition of the intervertebral discs, vertebral bodies or supporting soft tissues including traumatic causes (sprains and strains) resulting in weakness of lower back muscles, tendons and ligaments. Other causes may include degenerative arthropathies, infection, and rarely tumour Koes B and Van-Tudler M (2006) as well as emotional and cognitive factors Akinbo SRA (1998). Disability reported as a result of low back pain and loss of manpower with huge amount of revenue loss has increased dramatically lately Akinbo SRA (1998). Most LBP cases recover spontaneously over a few days; however, about $5 \%$ to $10 \%$ eventually develop to chronic stage while $1 \%$ may progress to even more disabling conditions Jameel IM and Robinson JS (1996). Over a century of intense study on low back pain has produced no clear understanding of common place back pain Kuritzky L Barnett A Doan H, et al. (2002).

Chronic Low Back Pain (CLBP) is expressed as pain persisting for more than 12 weeks Bratton RL (1999) and often classified according to the aetiology. While mechanical or non-specific CLBP has no serious underlying pathology or nerve root compromise, secondary CLBP (occurring in fewer patients) is associated with underlying pathology Kuritzsky L Barnett A Doan $\mathrm{H}$ et al (2002). Non-specific CLBP is a major source of disability affecting the working population and represents $85 \%$ of

\section{Correspondence Author:}

Okafor Chris

Physiotherapy Department

College of Medicine,

University of Lagos,

Lagos,

Nigeria

Email: uacokafor@cmul.edu.ng 
the patients reported, thereby exerting a huge cost on the patient, the family and the society Kuritzsky L Barnett A Doan $\mathrm{H}$ et al (2002). Predisposing factors include age, heredity, physical fitness, obesity, poor postural alignment, degenerative diseases of the spine Arteaga A Garcia C, Ibanez T Perez J Ramos J and Cazaro I (1995) psychological, psychosomatic and emotional susceptibility Akinbo SRA (1998), Arteaga A Garcia C Ibanez T Perez J Ramos J and Cazaro I (1995). Initial treatments include activity and lifestyle modification, use of analgesic agents and patient education Steven $\mathrm{J}$ Atlas (2012).

Dance therapy is defined by the American Dance Therapy Association (ADTA) as the psychotherapeutic use of movement as a process which furthers the emotional, cognitive and physical integration American Dance Therapy Association (2009). Dance is a form of expressive movement therapy founded on the basis that movements and emotions are directly related Payne H (2006) which focuses on the interactive connection between the mind and body to promote health and healing. Aerobic dance effects changes in feelings, cognition, physical functioning, and behaviour. The theory underlying dance therapy is that body movement reflects the inner state of the human, and that by moving the body within a guided therapeutic setting, a healing process begins American Dance Therapy Association (2009). Popularity of dance therapy has increased since the 1940 s with its ultimate purpose to find a healthy balance and sense of wholeness in patients with various clinical pathologies Levy and Fran J (1988).

Pain relief effect of dance therapy is multi-factorial and may be as a result of the stabilizing and strengthening effects on the spinal musculature. It may also derive from psychological benefits that the body and mind interact so that a change in movement affects total functioning and improvement in coping strategies and exercise-induced muscle relaxation effects. While most emotional and physiological ailments often present in the body as muscle tension, dance provides a medium to release the muscle tension through movement, allowing the inner feelings expressed through movement Rydevik D Holms S and Brown MD (1996). Other benefits of dance include its perceived influence on pain gating mechanism and the release of pain relieving neuropeptides (endorphin and serotonin) at various levels of the central nervous system Rydevik D Holms S and Brown MD (1996). Various non pharmacological approaches to back care have been well explored in medical literature American Dance Association (2009). However, same cannot be said of the application of dance movement as a form of therapy. This study therefore aimed to investigate the effect of aerobic dance on pain intensity, functional disability and quality of life in patients with chronic low back pain.

\section{MATERIALS \& METHOD}

Thirty subjects ( 10 males and 20 females), aged between 30 and 75 years, with diagnosis of non-specific chronic low back pain participated in the study. They were recruited by non-probability consecutive sampling technique from the out-patient unit of the Department of Physiotherapy, Lagos University Teaching Hospital (LUTH) Idi-Araba, Lagos. Patients with co-existing malignancy, cardiac or pulmonary conditions were excluded from the study. Participants were randomised into two groups: a study group (A) which comprised 15 subjects (5 males and 10 females) with mean age of 55.7 years, and a control group (B), also of 15 subjects (5 males and 10 females) with mean age of 55.2 years. Both groups received conventional physiotherapy programmes which comprised timed application of radiant heat therapy, therapeutic exercises, back care education, and application of soft tissue manipulation (massage) with a specified topical non-steroidal anti-inflammatory gel to the painful low back region.

In addition to these, subjects in the study group (A) also received a protocol of aerobic dance which consisted of four stages: warm up, pre-course, main course and cool down stages. The warm up and cool down stages involved mainly breathing and stretching exercises whereas the main course stage involved aerobic dance, rolling exercises and specific back extension exercises in lying and standing postures. Entire dance session was conducted with the background of soft (high life) music and lasted for 45 minutes. All activities for both groups were conducted three times weekly for a study period of six weeks.

Visual Analogue Scale, Roland Morris Disability Questionnaire and Nottingham Health Profile Questionnaire were used as both pre- and post-interventional outcome measures for all subjects in the two groups (taken at the beginning and at the end of the six week study period). Data collected from returned questionnaires and measurements, were summarized using mean, standard deviation and frequency tables. Student T-test was used to analyze the data at $95 \%$ confidence interval.

Ethical approval was sought and obtained from the Health Research and Ethics Committee of the Lagos University Teaching Hospital prior to the commencement of the study

\section{PARTICIPANTS' OPINIONS}

(Opinions and comments expressed by randomly selected participants in the study group)

Subject 1: The exercises were very effective and made me feel really rejuvenated. I feel so good almost pain free; the exhilarating feeling of well being.

Subject 3: I felt great and refreshed and light after every dance exercise. I hereby suggest that dance therapy should be part of the normal clinic days for back and knee pains. The healing process/ rehabilitation is faster this way.

Subject 7: Indeed, the dance sessions made me feel lighter and younger. Each dance session made me feel much relieved.

Subject 13: Thank you so much for bringing me into this programme. To $m e$, it is a new and exciting area and I have really benefitted from the dance sessions.

\section{DISCUSSION}

The result from the study showed a significant difference between the pre- and post- assessment outcomes for the three measured variables (pain intensity, functional disability and quality of life) suggesting that both treatment approaches (conventional and dance) were effective in the management of chronic low back 
pain. This is in agreement with findings by Chan CW Mok NW and Yeung EW (2011) in a randomized controlled study which combined both conventional physiotherapy modalities with aerobic protocol. Their results showed that both conventional physiotherapy techniques and aerobic exercises were of significant benefit in the management of pain symptom and functional disability resulting from chronic low back pain. However, no difference was reported when their therapeutic efficacies were compared Chan CW Mok NW and Yeung EW (2011).

A comparison of the treatment effects (mean change) between the two groups for pain, functional disability and quality of life (QoL) indicates a significant improvement in favour of the study group. Also, findings from this study indicate effectiveness of the treatment interventions for both groups in line with findings from previous studies Chan CW Mok NW and Yeung EW (2011) Magnusson ML Chow DH Diamondopoulos Z Pope MH (2008) Detori DG (1995). The preand post-treatment analysis of pain,

Table 1: Analysis of Pain, Functional disability and Quality of Life of Subjects in both groups (Pre- and Post-treatment).

\begin{tabular}{|l|l|l|l|}
\hline & Pre-treatment & Post-treatment & P-value \\
\hline GROUP A & & & \\
\hline Pain intensity & $6.63 \pm 1.1$ & $3.32 \pm 1.22$ & $0.0001^{\star}$ \\
\hline Functional disability & $55.1 \pm 25.8$ & $25.0 \pm 20.8$ & $0.0015^{\star}$ \\
\hline Quality of life & $70.5 \pm 26.8$ & $27.9 \pm 19.4$ & $0.0001^{\star}$ \\
\hline GROUP B & & & \\
\hline Pain intensity & $7.03 \pm 2.01$ & $4.89 \pm 1.19$ & $0.0014^{\star}$ \\
\hline Functional disability & $11.4 \pm 5.31$ & $10.9 \pm 4.46$ & $0.0189^{\star}$ \\
\hline Quality of life & $18.7 \pm 6.89$ & $13.7 \pm 5.9$ & $0.0417^{\star}$ \\
\hline
\end{tabular}

* indicates significant difference at $p<0.05$.

Table 2: Comparison of the treatment effects (pre/post) on Pain, Functional disability and Quality of life among Subjects in both groups.

\begin{tabular}{|l|l|l|l|}
\hline & $\begin{array}{l}\text { GROUP A } \\
\text { (Pre/Post) }\end{array}$ & $\begin{array}{l}\text { GROUP B } \\
\text { (Pre/Post) }\end{array}$ & P- Value \\
\hline Pain intensity & $3.89 \pm 1.38$ & $1.42 \pm 0.95$ & $0.0001^{*}$ \\
\hline Functional disability & $27.3 \pm 15.7$ & $1.09 \pm 0.30$ & $0.0001^{*}$ \\
\hline Quality of life & $35.4 \pm 19.5$ & $2.27 \pm 1.28$ & $0.0001^{*}$ \\
\hline
\end{tabular}

* indicates significant difference at $p<0.05$.

functional disability and quality of life of subjects in both groups showed that while there was significant difference in all studied parameters, a more significant improvement was reported for pain intensity in the study group compared with that of functional disability and quality of life domains. In previous but related studies, Detori DG (1995) found a significant difference in pain intensity and functional disability in patients with low back pain 6 to 12 months after treatment regardless of randomization into either a flexion exercise or back extension exercise while Bendix F (2002) also reported a similar result in a study comparing pain intensity and functional disability in patients with low back pain undergoing intensive physical training programme.

The effectiveness of dance therapy as reported by the study show is further in with previous studies which have documented the effectiveness of dance therapy for some physiological problems including its role in reducing test anxiety ERWIN-Grabner T Goodwill SW Hill ES Neida KV (1999) and in thera- 


\section{CONCLUSION}

Study outcomes show that conventional physiotherapy comprising intervention with radiant heat, therapeutic exercises, back care education, back extension exercises and application of soft tissue manipulation (massage) with a specified topical non-steroidal anti-inflammatory gel showed significant effect on pain intensity, functional disability and quality of life in chronic low back pain. However, dance therapy in combination with conventional physiotherapy produced a more significant effect in reduction of pain intensity, functional disability and improving quality of life in patients with chronic low back pain. Treatment sessions incorporating dance therapy may therefore be considered as a possible treatment option in the management of pain, functional disability and quality of life in individuals with chronic low back pain.

\section{LIMITATION}

The study would have been stronger with the inclusion of a non-treatment group as the control group, however, this was not considered ethical or practicable with the study design chosen.

\section{REFERENCES}

Akinbo SRA (1998). Physiotherapy management of low back pain; Manipulative Therapy and Thermal Therapy Techniques. Journal of the Nigeria Medical Rehabilitation Therapists (3):32-34.

American Dance Therapy Association (2009): "Who We Are," http://www.adta.org/about/who. cfm. Retrieved on 23/05/09.
Arteaga A, Garcia C, Ibanez T, Perez J, Ramos J and Carazo I (1995). Introduction to mechanica low back pain (29):128-35.

Bendix F (2000). Physical measurements as risk indicators for low back trouble over a one year period. Spine (9):106-119.

Bratton RL. (1999) Assessment and management of acute low back pain. American Family Physician; 60: 2299-308. Available at: www.aafp. org/afp/991115ap/2299.html. Accessed April 4, 2003.

Chan CW, Mok NW and Yeung EW (2011). Aerobic exercise training in addition to conventional physiotherapy for chronic low back pain: a randomized controlled trial. Arch Phys Med Rehabil. 92 (10):1681-5

Detori DG (1995) Low back pain: Medical diagnosis and comprehensive management (30-33) Philadephia: WB Saunders.

Erwin-Grabner T, Goodill SW, Hill ES, Neida KV (1999). Effectiveness of Dance/Movement Therapy on Reducing Test Anxiety. Retrieved from: http://www.springerlink.com/content.

Jameel IM and Robinson JS (1996) Residual Post-Surgical back pain. Journal of Medical Association of Georgia (85): 107-107.

Koes B and Van-Tudler M (2006). 'Low back pain (acute)'. Clinical evidence (15):1619- 33.

Kuritzky L, Barnett A, Doan H, et al. (2002) The10-minute examination for low back pain. J. Musculoskelet Med. 19: 497-505.

Levy and Fran J (1988). Dance Movement Therapy: A Healing Art. The American Alliance for Health, Physical Education, Recreation, and Dance (1): 1 .

Lundy H and McGuffin P (2005). Using Dance/ Movement Therapy to Augment the Effectiveness of Therapeutic Holding with Children. Journal of child and adolescent psychiatric nursing, 3, 135-145.

Magnusson ML, Chow DH, Diamandopoulos Z, Pope MH (2008). Motor control learning in chronic low back pain. Spine 15;33 (16): E532-8.

Martin Friedrich, Georg Gittler, Yvonne Halberstadt, Thomas Cermak, Ingrid Heiller (1998). Combined exercise and motivation programme: Effect on the compliance and level of disability of patients with chronic low back pain: A randomized controlled trial. Archives of Physical Medicine and Rehabilitation 79 (5) 475 487.

Payne H (2006). Dance Movement Therapy, Research and Practice (2): 1-3.

Rydevik D, Holms S, and Brown MD (1996). Nutrition of spinal nerve roots; the role of diffusion from the cerebral spinal fluid. Trans Orthopaedic Res. Soc. (9):276.

Steven J Atlas (2010). Non Pharmacological treatment of Low Back Pain. The Journal of Musculoskeletal Medicine 27 (1) 1-9. 